\title{
Local Stress-Strain Behavior of a High-Temperature Steam Valve Under Transient Mechanical and Thermal Loading
}

\author{
Anżelina Marek and Jerzy Okrajni
}

\author{
(Submitted June 5, 2013; in revised form September 7, 2013; published online October 25, 2013)
}

\begin{abstract}
The problem of determining stress-strain characteristics in a selected component operating in a power plant is discussed. Steam valve in transient working conditions during a power unit start-up is taken as an example. The aim of the paper is to prove the possibility to use measurements of steam temperature and the temperature of selected points of the investigated elements for defining boundary conditions of the heat transfer problem as well as to verify operative correctness of the elaborated computer models. The essential importance of time-variable and non-uniform temperature field for the course of local stress changes that results in metal fatigue processes is shown. The method of the computer model validation is discussed as the one of important problems which should be solved if we wanted to predict properly the variable temperature field. The problem of materials behavior under mechanical and thermal loading in the selected component has been discussed.
\end{abstract}

Keywords boundary conditions, heat transfer coefficient, steam valve, thermo-mechanical fatigue

\section{Introduction}

The analysis of local conditions of deformation processes that determine the phenomenon of crack formation and growth is important in cases where the durability of a device is examined (Ref 1). It is one of the main problems encountered when designing and maintaining power plants. The intensity of these processes depends on the operation parameters and geometry of power plant components. It is necessary to use computer modeling methods and models with proper boundary conditions for the proper description of the process of deformation in such components. Thick-walled components of power pipelines, which are especially prone to crack formation and growth, may serve as an example here (Ref 2,3$)$. It is determined by the state of stress prevalent in those components and by the probability of the occurrence of material defects resulting from the mechanical aspects of connection with other installation parts and the production technology. In the case of thick-walled components, the action of non-uniform thermal field over time gains particular significance. In the majority of cases the value of anticipated stresses in components of the power generation units currently in operation is established during their design by analytical methods taking into account shape factors, as defined by standards (Ref 4, 5). Therefore, those components meet regulatory strength criteria. However, this approach to strength calculations is of less value in evaluating and forecasting the durability of a device. This is

Anżelina Marek and Jerzy Okrajni, Silesian University of Technology, Krasińskiego 8, 40-019 Katowice, Poland. Contact e-mail: anzelina.marek@polsl.pl.

because durability should be considered from a local perspective in connection with crack formation and growth phenomena.

A local approach to the strength analysis of power system components is particularly significant due to the need to evaluate the degree of degradation of the material properties of a power unit after many years of operation and in connection with the drive to improve the operating parameters of new units and to increase the availability of the existing systems. In this case, a methodical and detailed analysis of the behavior of the components of a power generation unit under various operating conditions may be of some value. In the paper, this analysis has been conducted for the body of a main steam valve. Valves in high-power units are large, thick-walled devices of complex shapes. In main steam pipelines, under conditions of unit startup and shut-down, large differences between the temperature of inner and outer surfaces of valves occur. Significant deformations and thermal stresses are the result of a non-uniform thermal field present in such conditions (Ref 6-11).

\section{Main Steam Valve Operating Conditions Characteristics}

The main steam valve is a simple mechanism (Fig. 1). Its prime component is the body, which consists of two thickwalled vessels (1 and 2 in Fig. 1) welded together, inside of which a seal in the form of a sleeve (3-Fig. 1) is located. A gate (4-Fig. 1) that is moved vertically by its mechanism interacts with the seal. The body of the main steam value is made of 13HMF (14MoV6-3) steel.

The gate opens the valve by moving upward and allows the flow of steam. As a result of moving downward, the gate is pressed against the seal, closing the valve and shutting off the inflow of steam to the turbine. Sensors placed in the body of the valve ensure constant control and registration of local values of the temperature at different times, which is especially important 


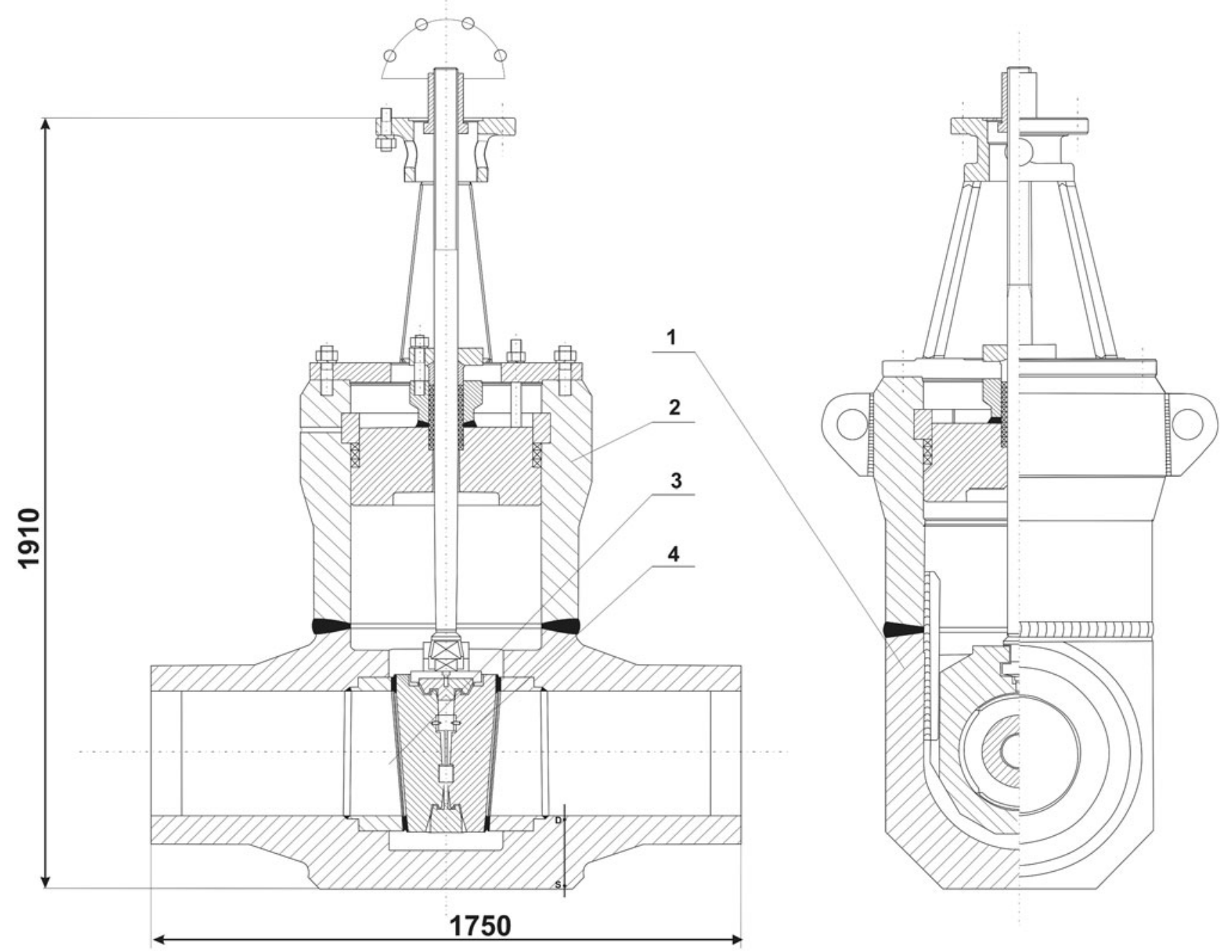

Fig. 1 Design diagram of the main steam valve with marked points near which temperature measuring sensors are located (S-shallow and D-deep)

at shut-off and start-up of the power generation unit. A power unit operation manual specifies the admissible variation between the temperature values measured by means of a thermocouples placed at different depths relative to the outer surface, i.e., located "deep" and "shallow" according to the outside surface of the valve body (Fig. 1). During unit operation, the parameters specifying its operating conditions are also registered. These include the steam pressure and temperature (Fig. 2).

The registered parameters are used by the staff to control the power generation unit. A constant registration of these parameters also ensures evaluation of the effect of operation on the degradation of functional properties of the installation and mainly on the phenomena of fatigue as well as crack formation and growth in the material of pipeline components. Based on the registered course of operation it is possible to estimate the loading history needed to assess the cumulated extent of damage. However, data gained from the measurements describe the behavior of the components from a global perspective relative to mechanical loads, whereas the temperature is determined in selected areas of the devices, which usually do not overlap with areas where material degradation processes are the most intensive.
Since fatigue processes occur with various intensities in particular areas of the components, depending on the course of the temperature and stresses at different times, it is necessary to develop methods to enable the results obtained from measurements to be used in order to determine local characteristics of stresses and deformations over time. The paper presents an attempt to apply measurements taken in industrial conditions in the evaluation of the state of stress and strain in the body of the main steam valve being a thick-walled component in which temperature gradients especially intensively affect the value of thermal stresses.

\section{Model of the Component}

The model was isolated by means of mental intersections method, while taking into account the symmetry planes of the part of the component of the installation (Fig. 3). The influence of the characteristics of mechanical and thermal loads (Fig. 2) on the course of changes in temperature, stresses, and strains in the volume of the steam valve was examined. The influence of hangers and supports and dead weight was omitted. 


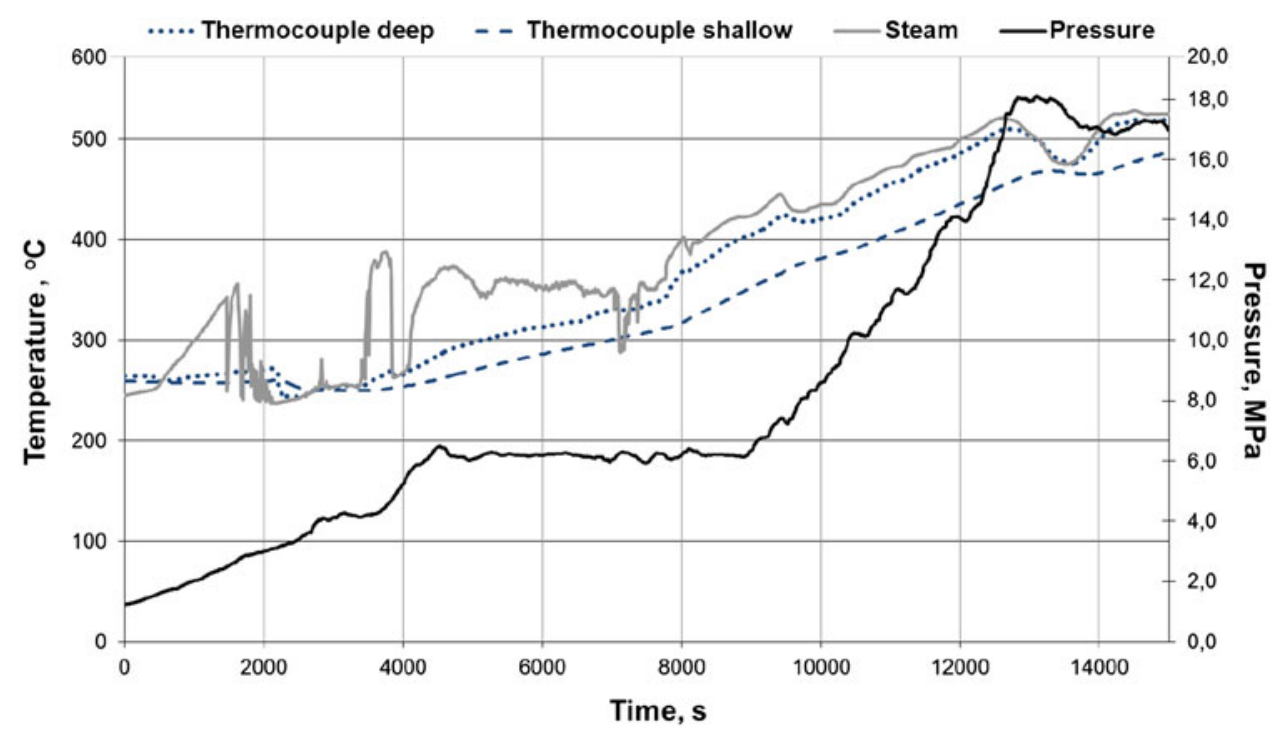

Fig. 2 Characteristics showing the changes of thermal and mechanical loads in the conditions of hot start-up

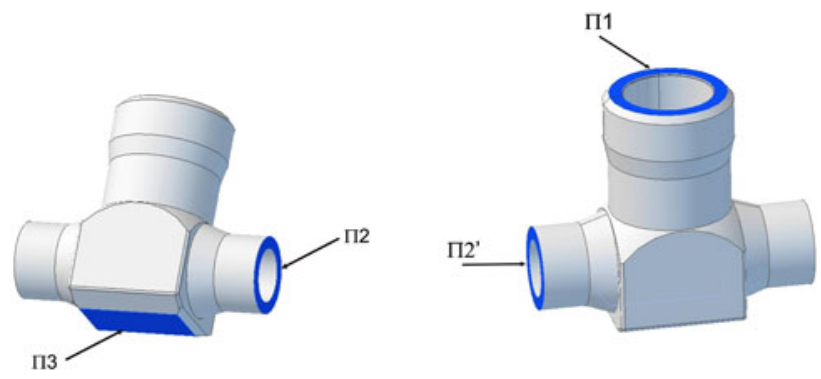

Fig. 3 Model of the main steam valve with marked planes where boundary conditions were adopted

At that stage of the calculations, the external forces were omitted in the planes of "intersections," $\Pi 1, \Pi 2$, and $\Pi 2$ ', through which the component was isolated from the pipeline. On surface П3, a limit was assumed for the dislocation in the direction of the pipeline $z$ axis, i.e., perpendicular to surface $\Pi 3$.

In symmetry planes of the gate body, a limitation of dislocation in directions vertical to those planes was assumed.

The characteristics of changes in pressure and temperature of the steam flowing through the valve in industrial conditions, obtained from the measurements taken during one of start-ups of the boiler (Fig. 2), were assumed for preliminary calculations. Specific thermal capacity of $486 \mathrm{~J} / \mathrm{kg}{ }^{\circ} \mathrm{C}$, thermal conductivity of $25 \mathrm{~W} / \mathrm{m}^{\circ} \mathrm{C}$, and density of $7870 \mathrm{~kg} / \mathrm{m}^{3}$ were adopted for the 13HMF steel. On the inner surface of the chamber a heat transfer coefficient taken from the broad range of values given in reference (Ref 12) for steam was adopted or the heat transfer has been assumed as constant $\alpha=$ $1000 \mathrm{~W} / \mathrm{m}^{2}{ }^{\circ} \mathrm{C}$ that is suggested by the standards (Ref 4). Due to insulation, heat exchange on the external surface was assumed as constant with small value $\alpha=5 \mathrm{~W} / \mathrm{m}^{2}{ }^{\circ} \mathrm{C}$ in the transitional period during the start-up of the boiler. For the adopted boundary conditions and material constants, the temperature distributions in the valve body volume over time were then determined.

Due to the possibility of stresses exceeding the yield point in the component, a thermo-elastic-plastic model of material, whose characteristics are shown in Fig. 4, was used in order to

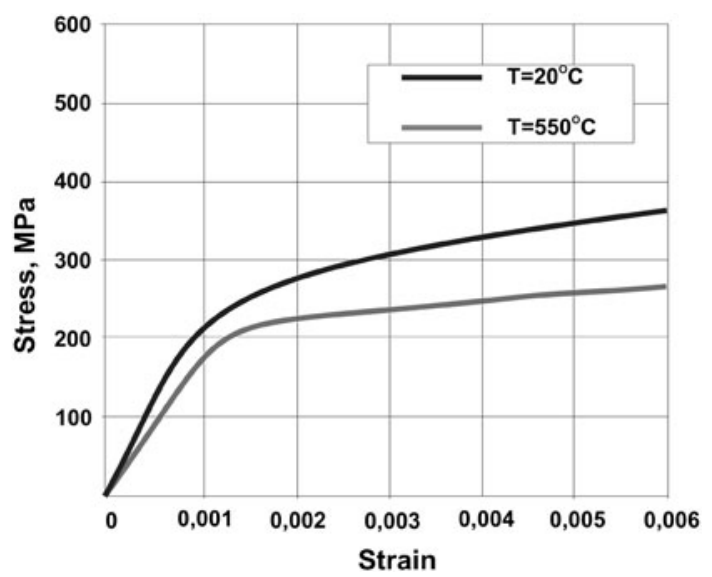

Fig. 4 Characteristics of the thermo-elastic-plastic material model adopted in the calculations of stress fields (13HMF steel-14MoV63)

determine stress and strain fields. These characteristics have been assumed as the cyclic stress-strain curves which have been determined on the basis of isothermal low-cycle fatigue tests. It was also assumed that the linear thermal expansion coefficient depends on temperature and the dependence for the material could be expressed as a formula:

$$
\begin{aligned}
\beta= & -2.265 \cdot 10^{-14} \cdot T^{3}+2.609 \cdot 10^{-11} \cdot T^{2} \\
& -4.312 \cdot 10^{-9} \cdot T+1.2 \cdot 10^{-5}
\end{aligned}
$$

where temperature $T$ should be given in ${ }^{\circ} \mathrm{C}$ and the coefficient $\beta$ is expressed in units: $1 /{ }^{\circ} \mathrm{C}$.

\section{Calculations of Temperature and Stress Fields}

Two cases were analyzed. First, a constant heat transfer coefficient of $1000 \mathrm{~W} / \mathrm{m}^{2}{ }^{\circ} \mathrm{C}$ was assumed on the inner surface and was subsequently treated as the time-dependent property. The characteristic of the heat transfer coefficient as a function of time have been worked out to obtain concordance between 


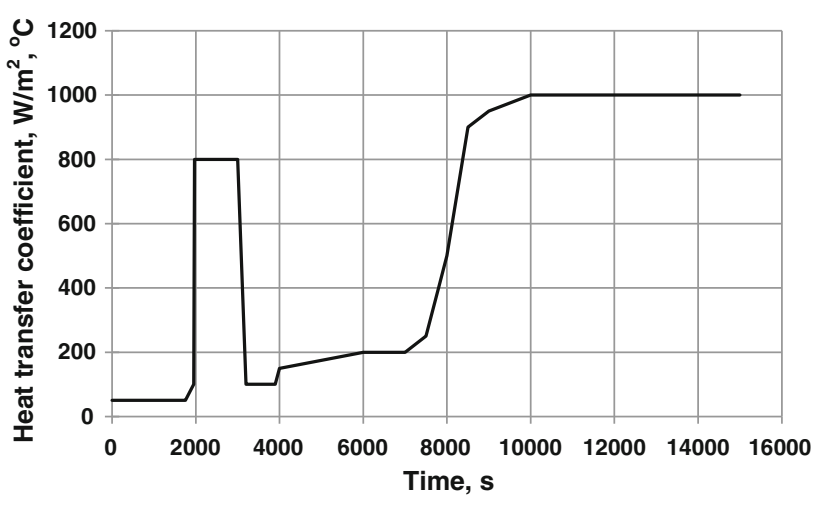

Fig. 5 Characteristics showing the changes of heat transfer coefficient

the temperature measurements and the value calculated by the FEM analysis. This paper, therefore, proposes to introduce a heat transfer coefficient as a function of time, taking values from the ranges shown in the literature, as for instance in the book of Orłoś (Ref 12). The assessment can be performed taking into account changes of pressure and the rate of fluid flow inside the pipeline. In this situation it is possible to define a large set of different characteristics, that have to be validated and the appropriate values selected from this set.

It could be argued that a comparison of the values of the temperature measured at the selected points of the valve with the calculated data is an appropriate method for this selection. This comparison shows the value of plotting temperature changes over time in real conditions as well as the figures predicted by the model. Figure 5 presents the diagram of the heat transfer coefficient changes in time that was used.

Characteristics of the temperature at different times were determined at points that were close to the places, where thermocouples are located under industrial conditions. Figure 6 illustrates a comparison of the characteristics of variations in temperature as a function of time, based on a computer model with characteristic determined experimentally.

In the Fig. 6, the characteristics calculated for the changeable and constant heat transfer coefficient have also been compared. A greater relationship between diagrams from the model with measurements for the changeable heat transfer coefficient may be observed.

One should note that the heat transfer coefficient depends on the state of the medium and in the case of power generation units, various values of this coefficient should be adopted, depending on the phase of the technological cycle. This problem is a separate issue, on which work is currently underway.

For the model described the different temperature distributions over time were calculated. Some examples are shown in Fig. 7.

The temperature field determined on the basis of the model approach was then used to calculate variable stresses. At hot start-up of the installation, the components of stress and strain state were calculated as a function of time. Examples of stress distribution on the surface of the valve and its cross sections with symmetry planes for selected instants are presented in Fig. 8.

Local material fatigue caused by temperatures at different times is characterised by the course of changes of the stress components and reduced stress as a function of time in the
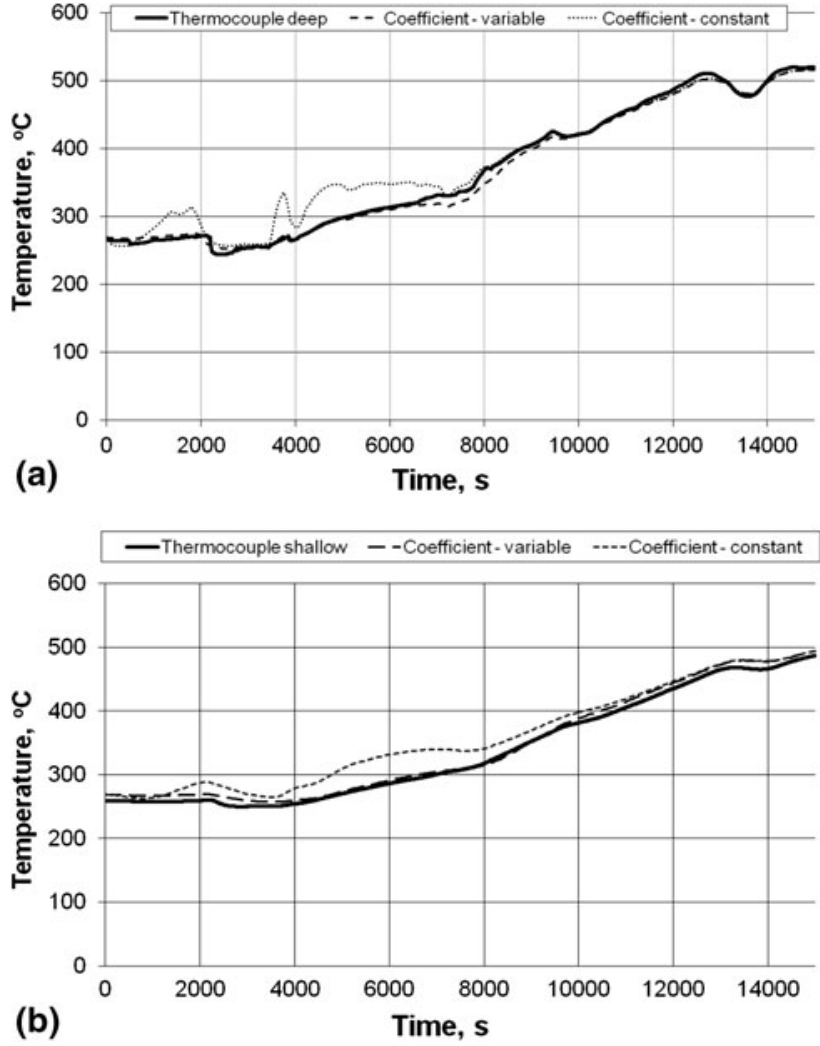

Fig. 6 Courses of variations in temperature over time in the conditions of unit start-up, determined using thermocouples placed shallow and deep under the outer surface of the valve and characteristics determined on the basis of calculations for model points located near the measuring points located deep-(a) and shallow-(b) for the thermocouple according to the outer surface of the valve

selected points of the valve. These courses are shown in Fig. 9. The points, in which the characteristics presented in Fig. 9 were determined, had been selected on the basis of a stress distribution analysis, while focusing on areas where the equivalent stress (Huber von Mises stress) changes have different character.

By comparing the characteristics shown in Fig. 9 the course of changes in stress over time may be seen to be considerably different, depending on the position of a point on the inner surface. The characteristics shown in Fig. 9 reveal that the temperature at different times significantly affects the variable stress in point $\mathrm{M}$, while the course of changes in stress over time in point $\mathrm{N}$ reveals mainly the action of pressure which increases during the start-up. The points used as examples to demonstrate the stress and temperature variations have been chosen taking into consideration different mechanisms of the possible damage processes in the material connected with the stress values and their variability. In point $\mathrm{M}$, the main process of material damage could be argued to be creep because of the low value of the changeable stress range. On the contrary, in point $\mathrm{N}$ it appears that the high values of the changeable stress range indicate a possible strong influence of thermal loading on the material fatigue process.

On the inner surface of this complex-shaped and thickwalled component we can find points for which the stress state strongly depends on the changeable temperature field, as for instance point $\mathrm{M}$. We can find the areas in which stress state 


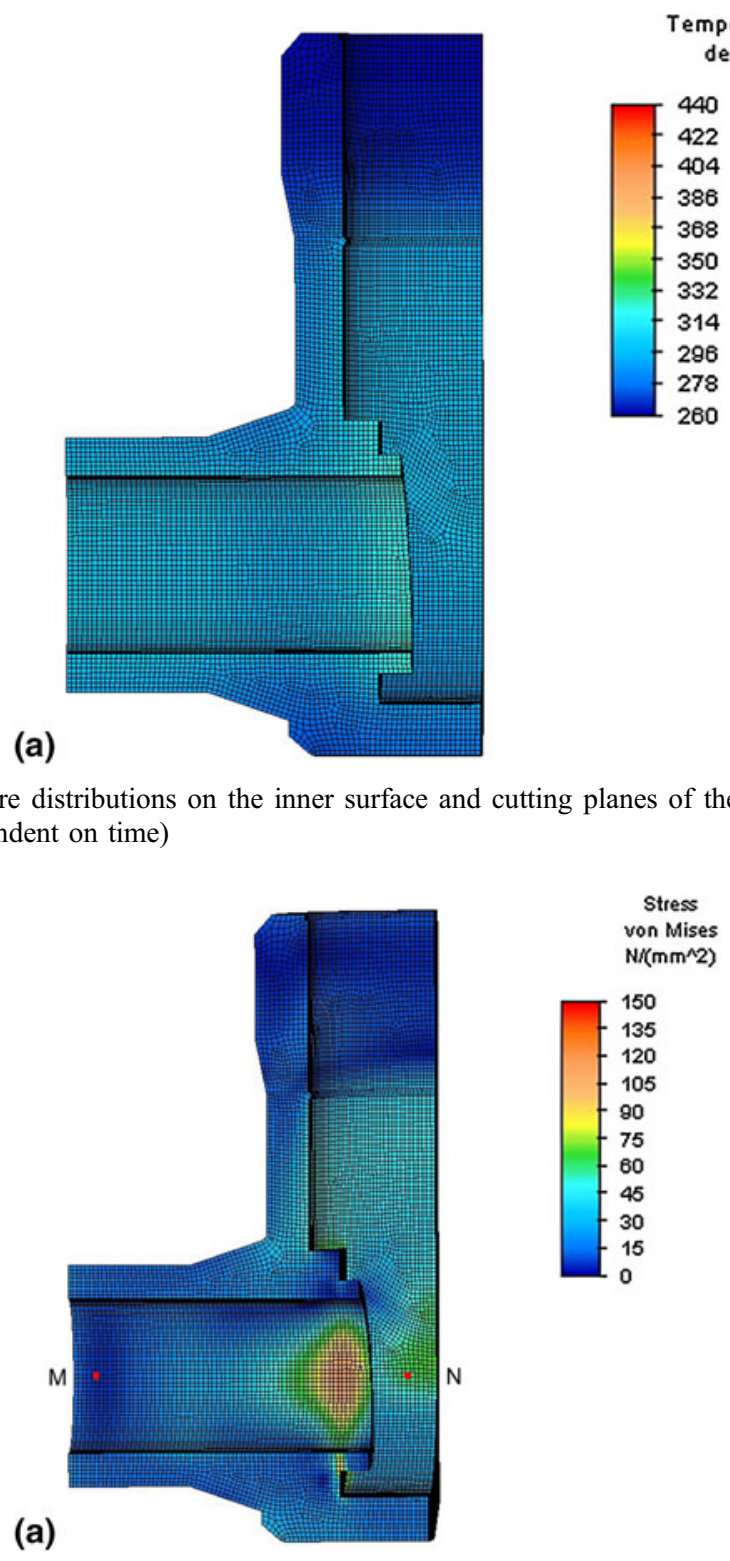

(b)

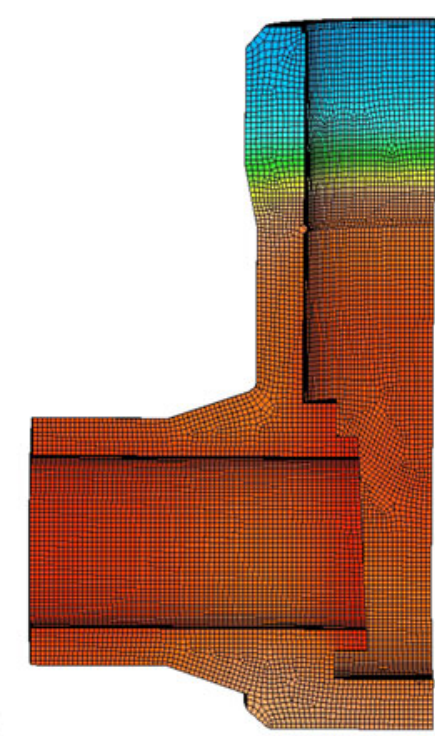

Fig. 7 Temperature distributions on the inner surface and cutting planes of the valve for selected instants: (a) $5000 \mathrm{~s}$, (b) $10,000 \mathrm{~s}$ (form the $\alpha$ coefficient as dependent on time)

(a)

(b)

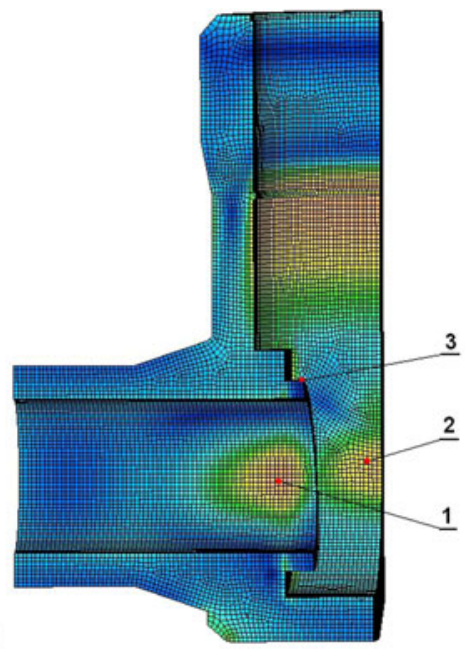

Fig. 8 Distribution of reduced stresses on the inner surface and cutting planes of the valve for selected instants: (a) $5000 \mathrm{~s}$, (b) $10,000 \mathrm{~s}$

depends mainly on the pressure, as with the area close to point N. It is possible to say that in the areas strongly influenced by temperature the fatigue process will probably take place. In this case, the stress-strain characteristics would be necessary to access the intensity of this type of fatigue. The examples of the relationships between the strain and stress state components have been shown in Fig. 10. It was shown that, at the selected points, stresses temporarily exceed the yield point value, which can lead to material fatigue within the range of a small number of loading cycles. This is a special kind of low-cycle fatigue process.

The mechanical strain-stress diagrams show that in the chosen areas the deformation process has an elasto-plastic character. The dependence between the temperature field and mechanical strains and stresses suggests that a thermo-mechanical fatigue process may occur in these areas.

This is of particular relevance in the case of thick-walled components. It would be particularly important in the case of the plants with increased parameters of operation for which the new materials are used, with the higher values of thermal expansion coefficients and sometimes with structure, which changes during cyclical elasto-plastic deformation process.

\section{Analysis of Calculation Results}

The calculations show a particularly important influence of temperatures at different times on the value of instantaneous stresses in the component. At the initial stage of the boiler startup, thermal stress considerably exceeds the value of stresses caused by internal pressure. This leads to an important conclusion for designers and users of power installations.

When we examine fatigue-like processes, thermal interactions should be considered the basic load affecting thick-walled components of complex shapes.

Mechanical interactions, mainly pressure, are of minor importance in this case. Stresses resulting from the action of pressure will, however, determine creep and relaxation phenomena which occur over long periods of time at practically steady loads. 

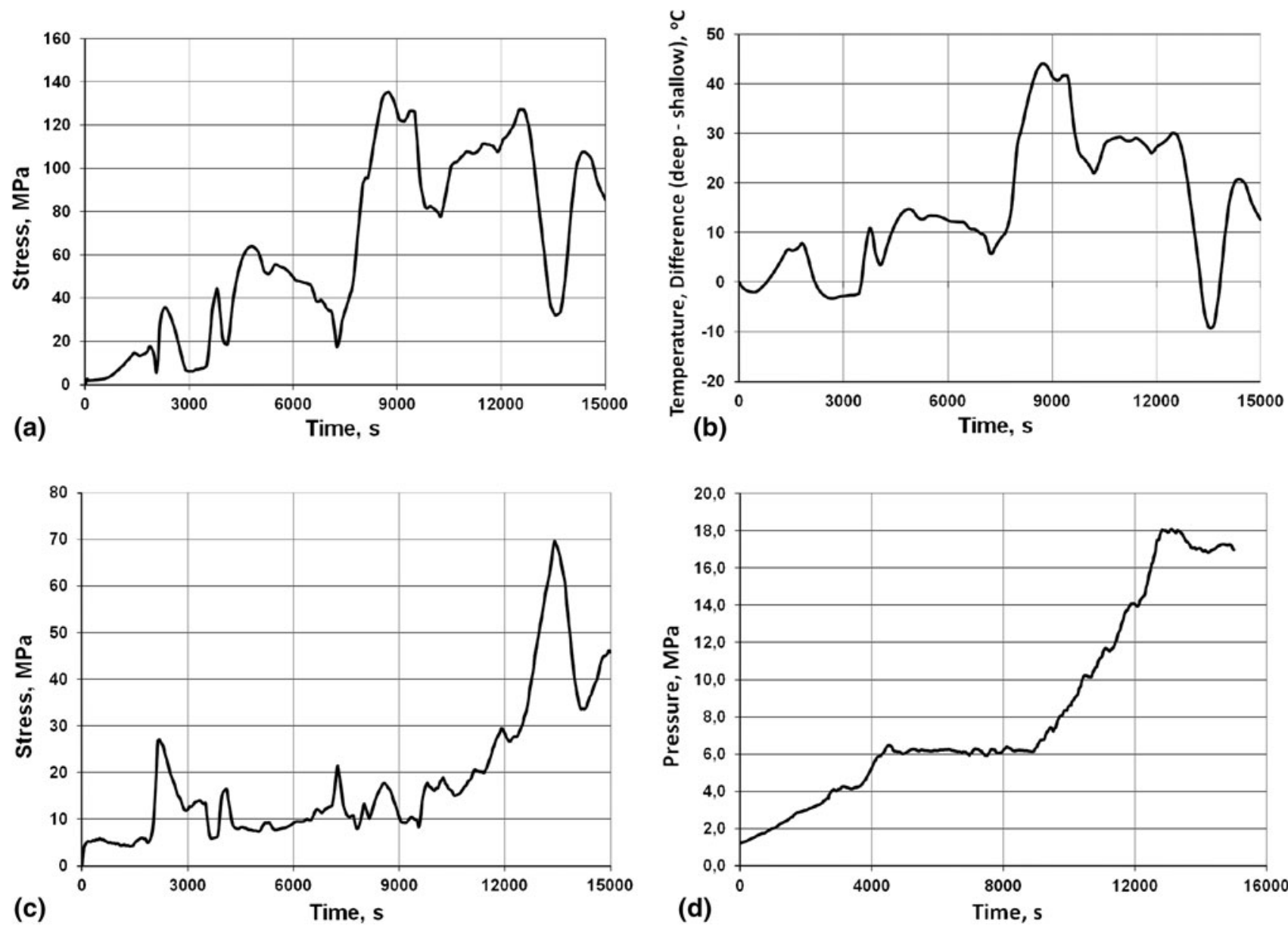

Fig. 9 The course of changes in reduced stresses over time determined for point M (Fig. 8) - (a), the difference between temperature for thermocouple deep and thermocouple shallow-(b), the course of changes in reduced stresses over time determined for point $\mathrm{N}$ (Fig. 8) - (c), pressure- (d)

The calculations show that the material on the inner surface of the gate body is exposed under operating conditions to interactions which may induce thermo-mechanical fatigue. This is evidenced by the values of stresses at different times and by the interdependence of changes in the temperature and stress over time. The variable stresses that have been identified may constitute a valid reason to pay more attention to the fatigue processes occurring in power installations, induced by varying temperatures.

A solution to the problem of determining the durability in thermo-mechanical fatigue conditions in the case under consideration requires an accurate analysis of temperature distribution at different times which should be analyzed in detail and evaluated while taking into account their influence on the accumulation of fatigue damage. The simplest first approximation in this evaluation may consist of the results obtained with the use of the PN-EN 129052-4 (Ref 5) standard which contains an algorithm to forecast durability based on the characteristics of variable circumferential stresses. The quoted standard does not take into account, however, the effect of a simultaneous action and interdependence of variable temperature and stresses, for it treats fatigue as a phenomenon induced by changes of stress in steady ranges of temperature.

There are numerous conclusions that may be drawn from the discussion presented above, one of which is that, while examining the accumulation of damage in the material of thick-walled pipeline components, one should pay more attention to the fatigue process caused by the synergistic interaction of variable temperatures and stresses at different times (Ref 13-20), for which approximation is possible by a comparison with isothermal fatigue only in some cases. In this case, the results obtained from the study would form the basis for determining the characteristics of this fatigue process. In this sense, the research results presented in the paper could contribute to the identification of the determinants of the fatigue process.

In this paper, the authors have focused on exemplifying complex fatigue phenomena including, in particular, the examination of the behavior of a component of the selected device. The above-presented discussion also allows the formulation of practical conclusions, such as the following:

Unsteady operation of a pipeline, especially in the case of subsequent boiler start-ups, induces thermal stresses which may exceed the values of yield stress in components of complex shapes, which can significantly influence fatigue durability of the components.

A combination of computer modeling methods with an analysis of the results of local temperature measurements in selected components of a steam pipeline allows the effects of the mechanical and thermal interactions at different times to be evaluated. 

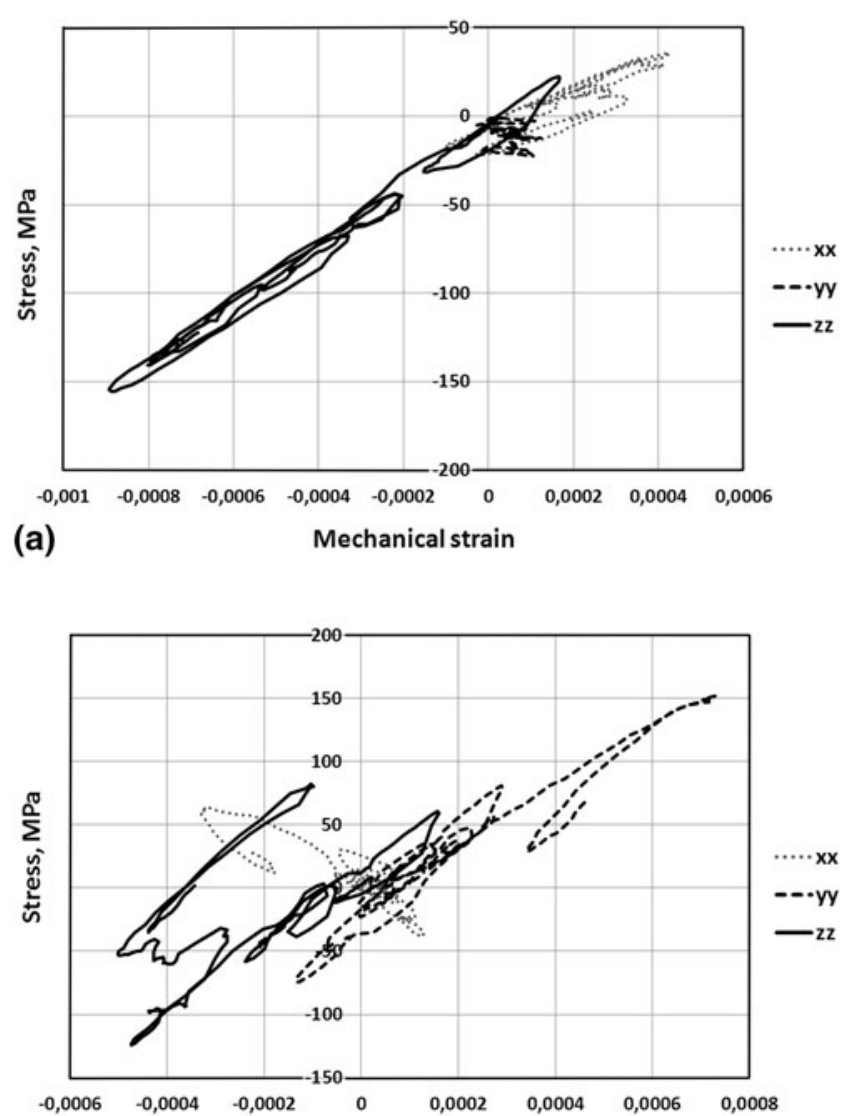

(c)

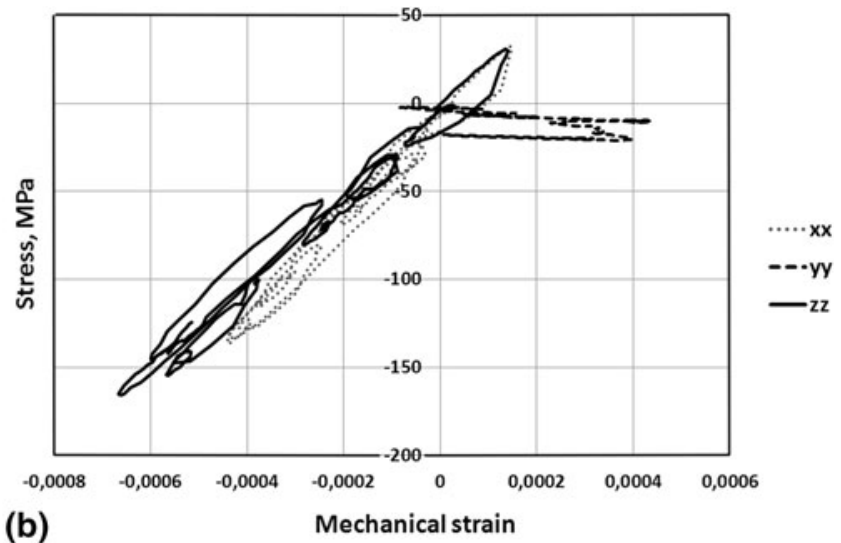

(b)

Mechanical strain

Fig. 10 Courses of stress components changes as a function of mechanical strain components determined for point 1 (Fig. 8)-(a), courses of stress components changes as a function of mechanical strain components determined for point 2 (Fig. 8) - (b), courses of stress components changes as a function of mechanical strain components determined for point 3 (Fig. 8) - (c)

The above-presented discussion is an attempt at a methodical presentation of an analysis of the behavior of selected thick-walled components of a steam pipeline that are subject to fatigue induced by a variable temperature. This presentation is based on computer models that require validation on the basis of results of tests carried out in industrial conditions. With this approach, the case of evaluating the state of stress in the main steam valve can be a contribution to the description of mechanical and thermal determinants of material properties degradation processes.

The discussion leads to a conclusion that it is necessary to pay particular attention to the need to combine operational tests with an on-going strength analysis of devices subject to mechanical and thermal interactions.

The presented work shows some aspects of the mechanical behavior analysis of the component that works under mechanical and thermal loading. Particular attention has been paid to two problems: the influence of the boundary conditions on the stressstrain characteristics; on the validation of the computer model.

The problem of fatigue life prediction will be analyzed in future works and the methodology presented may be useful in this case.

At this stage of investigation the cyclic stress-strain curve has been taken as a material model. Taking into consideration the thermo-mechanical character of the local fatigue process in future it will be necessary to look for new more exact material models based on the thermo-mechanical fatigue tests. These tests are under investigation and their results will be taken into consideration in future works, which will be the continuation of the problems shown in the paper.

\section{Conclusions}

1. The main reason for material fatigue in the components under investigation is temperature, which fluctuates, particularly during transient periods of plant operation.

2. One of the important features that influence the fatigue behavior of the component under investigation is a variable heat transfer coefficient on its inner surface.

3. Thermo-mechanical fatigue may play a very important role in power plant component damage.

4. A combination of computer modeling methods with an analysis of results of local temperature measurements in the steam pipeline components selected allows evaluation of the effects of the mechanical and thermal interactions at different times.

\section{Acknowledgments}

The results presented in this paper were obtained from research work co-financed by the National Centre of Research and 
Development in the framework of Contract SP/E/1/67484/ 10- "Strategic Research Programme-Advanced Technologies for obtaining energy: Development of a technology for highly efficient zero-emission coal-fired Power units integrated with $\mathrm{CO}_{2}$ cap."

\section{Open Access}

This article is distributed under the terms of the Creative Commons Attribution License which permits any use, distribution, and reproduction in any medium, provided the original author(s) and the source are credited.

\section{References}

1. J. Okrajni, A. Marek, and G. Junak, Description of the Deformation Process Under Thermo-mechanical Fatigue, J. Achiev. Mater. Manuf. Eng., 2007, 21(2), p 15-23

2. A. Neimitz, I. Dzioba, M. Graba, and J. Okrajni, Ocena wytrzymałości, trwałości i bezpieczeństwa pracy elementów konstrukcyjnych zawierajacych defekty (The Assessment of the Strength and Safety of the Operation High Temperature Components Containing Crack), Kielce University of Technology Publishing, Kielce, 2008 (in Polish)

3. D. Renowicz and M. Cieśla, Crack Initiation in Steels Parts Working in Boilers and Steam Pipelines, J. Achiev. Mater. Manuf. Eng., 2007, 21(2), p 49-52

4. European Standard PN-EN 12952-3:2004, Water-Tube Boilers and Auxiliary Installation, Part 3: Design and Calculation for Pressure Parts

5. European Standard PN-EN 12952-4, Water-Tube Boilers and Auxiliary Installation, Part 4: In-Service Boiler Life Expectancy Calculations

6. J. Okrajni, G. Junak, and A. Marek, Modelling of the Deformation Process Under Thermo-mechanical Fatigue Conditions, Int. J. Fatigue, 2008, 30(2), p 324-329

7. T.P. Farragher, S. Scully, N.P. O’Dowd, and S.B. Leen, Development of Life Assessment Procedures for Power Plant Headers Operated Under Flexible Loading Scenarios, Int. J. Fatigue, 2013, 49, p 50-61
8. J. Zieliński, J. Dobrzański, and T. Jóźwik, Assessment of Loss in Life Time of the Primary Steam Pipeline Material After Long-Term Service Under Creep Conditions, J. Achiev. Mater. Manuf. Eng., 2012, 54(1), p $67-74$

9. J. Okrajni, K. Mutwil, and M. Cieśla, Wytrzymałościowe kryteria oceny stanu rurociągów energetycznych po wieloletniej eksploatacji (Strength Criteria for an Assessment of Power Pipelines Condition After Many Years' Operation), Energetyka, 2001, 9, p 528-533 (in Polish)

10. W. Nowak, "Materiałowe i techniczne uwarunkowania trwałości komór przegrzewaczy pary kotła (Material and Technical Determinants of the Durability of Steam Superheater Chambers of Boiler BB1150)," Ph.D. Thesis, The Main Library of the Silesian University of Technology, 2003 (in Polish)

11. A. Hernas and J. Dobrzański, Durability and damage of boiler and steam turbine components, Publishing House of the Silesian University of Technology, Gliwice, 2003

12. Z. Orłoś, Ed., Naprężenia cieplne (Thermal stresses), PWN, Warsaw, 1991 (in Polish)

13. J. Okrajni, K. Mutwil, and M. Cieśla, Steam Pipelines' Effort and Durability, J. Achiev. Mater. Manuf. Eng., 2007, 22(2), p 63-66

14. J. Okrajni, A. Marek, and G. Junak, Stress-Strain Characteristics Under Mechanical and Thermal Loading, J. Achiev. Mater. Manuf. Eng., 2007, 20(1-2), p 271-274

15. A. Marek, G. Junak, and J. Okrajni, Fatigue Life of Creep Resisting Steels Under Conditions of Cyclic Mechanical and Thermal Interactions, Arch. Mater. Sci. Eng., 2009, 40(1), p 37-40

16. J. Okrajni, Computer Models of Steam Pipeline Components in the Evaluation of Their Local Strength, J. Achiev. Mater. Manuf. Eng., 2010, 39(1), p 71-78

17. J. Bressers and L. Remy, Ed., Fatigue Under Thermal and Mechanical loading, Kluwer, Amsterdam, 1996

18. P. Hähner et al., Research and Development into a European Code-ofPractice for Strain-Controlled Thermo-mechanical Fatigue Test, Int. J. Fatigue, 2008, 30(2), p 372-381

19. H. Sehitoglu, Thermal and Thermo-mechanical Fatigue of Structural Alloys, Fatigue and Fracture, Vol, 19, ASTM Handbook, West Conshohocken, PA, 2008, p 527-556

20. S.S. Manson, Thermal Stress and Low Cycle Fatigue, McGraw-Hill, New York, NY, 1966 